\title{
Hemin inhibits cyclin D1 and IGF-1 expression via STAT5b under hypoxia in ERo-negative MDA-MB 231 breast cancer cells
}

\author{
EUN-JOUNG LIM ${ }^{1 *}$, YOUN-HEE JOUNG ${ }^{1}$, SE-MI JUNG ${ }^{1}$, SE HYUNG PARK ${ }^{1}$, JIN HEE PARK $^{1}$, \\ SANG YOON KIM ${ }^{1}$, TAE SOOK HWANG ${ }^{1}$, DAE YOUNG HONG ${ }^{2}$, SO CHUNG CHUNG ${ }^{3}$, SANG-KYU YE ${ }^{4}$, \\ EON-SOO MOON ${ }^{5}$, EUI U. PARK ${ }^{6}$, TAEKYU PARK ${ }^{7}$, ILL-MIN CHUNG $^{8 *}$ and YOUNG MOK YANG ${ }^{1}$ \\ ${ }^{1}$ Department of Pathology, School of Medicine, and Institute of Biomedical Science and Technology, Konkuk University, \\ Seoul 143-701; ${ }^{2}$ Department of Emergency Medicine, Konkuk University Hospital; ${ }^{3}$ Department of Pediatrics, \\ School of Medicine, Konkuk University, Seoul 143-729; ${ }^{4}$ Department of Pharmacology, College of Medicine, \\ Seoul National University, Seoul 110-799; Departments of ${ }^{5}$ Internal Medicine and ${ }^{6}$ Forensic Medicine, School of Medicine, \\ ${ }^{7}$ Bio-Food and Drug Research Center, Department of Biotechnology, College of Biomedical and Health Science, \\ Konkuk University, Chungju City 380-701; ${ }^{8}$ Department of Applied Life Science, College of Life \& \\ Environment Science, Konkuk University, Kwang Jin Ku Hwa Yang Dong, Seoul 143-701, Korea
}

Received November 12, 2009; Accepted December 16, 2009

DOI: 10.3892/ijo_00000608

\begin{abstract}
Cyclin D1 and insulin-like growth factor 1 receptor (IGF-1R) are key regulators of cell proliferation that are overexpressed in most breast cancers. The purpose of the present study was to investigate the molecular mechanism by which hemin exerts its inhibitory effects on aggressive breast cancer cells. We found that hemin regulates cyclin D1 and IGF-1R proteins and insulin-like growth factor-1 gene expression through STAT5b in breast cancer cells. We confirmed that STAT5b, cyclin D1, and IGF-1R is up-regulated by hypoxia, and the increased STAT5b binds strongly to the STAT5-binding sites contained within the distal 5'-flanking region of IGF-1 gene in breast cancer cells. EMSA studies showed that STAT5 binding activity to the IGF-1 and cyclin D1 promoter was distinctly decreased by hemin in STAT5b-transfected COS-7 or MDA-MB 231 cells. IGF-1 gene expression was also decreased by hemin in mammary epithelial cells. STAT5b expression was inhibited in siRNA experiments and by hemin, leading to decreased levels of IGF-1. These results provide a basis for molecular targets in cancer treatment via the STAT5b/IGF-1 or /cyclin D1 pathway in solid tumor cells.
\end{abstract}

Correspondence to: Dr Young Mok Yang, Department of Pathology, School of Medicine, and Institute of Biomedical Science and Technology, Konkuk University, Seoul 143-701, Korea

E-mail: ymyang@kku.ac.kr

${ }^{*}$ Contributed equally

Abbreviations: STAT, signal transducers and activators of transcription; IGF-1, insulin-like growth factor-1; ER $\alpha$, estrogen receptor- $\alpha$; EMSA, electrophoretic mobility shift assay; GAS, IFN- $\gamma$-activated sequence; FAC, ferric ammonium citrate

Key words: hemin, hypoxia, STAT5b, IGF-1, IGF-1R, cyclin D1, breast cancer cells, MDA-MB 231, gene expression, binding site
These data indicate that hemin inhibits the cyclin D1 and IGF-1 expression via STAT5b under hypoxia in ER $\alpha$-negative breast cancer cells. These findings are valuable toward understanding the role of hemin-induced inhibition of cyclin D1 and IGF-1 expression under hypoxia in invasive and metastatic breast cancer.

\section{Introduction}

Heme (ferroprotoporphyrin IX) is a prosthetic group found in a relatively large number of cellular hemoproteins (hemecontaining proteins) that carry out diverse biological functions. In its oxidized state, when it is known as hemin (ferriprotoporphrin IX), heme is bound less tightly to hemoglobin, and interacts more readily with alternative acceptor proteins and the lipid membranes of cells. Hemin (ferric chloride heme) is, as a natural agent, an essential growth promoter of early hematopoietic progenitors (BFU-Es, CFU-Es), and a potent inducer of globin gene activation. Hemin has therapeutic potential as a natural regulator of hematopoiesis, as well as an agent that protects hematopoietic cells from cytotoxic treatment (drugs, hypoxia, or other stimuli), for treatment of hematological and even neurodegenerative disorders (1).

Insulin-like growth factors (IGFs), including IGF-I and IGF-II, are a family of polypeptide growth factors structurally related to proinsulin (2). IGF-1 mediates many of the growthpromoting effects of growth hormones during post-natal life $(3,4)$. Interest in the role of the IGF axis in growth control and carcinogenesis has increased because elevated serum IGF-I levels are associated with three of the most prevalent cancers in the United States: prostate cancer, colorectal cancer, and lung cancer $(5,6)$. In 1998, Physicians' Health Study researchers reported that men with high IGF-1 blood levels run a greater risk of prostate cancer. Similar results for breast cancer in premenopausal women in the Nurses' Health Study were released the same year, and a solid association in the case of colorectal cancer was reported in 1999 (7). 
Cyclin D1 is amplified in about $15 \%$ of breast cancer cases. However, cyclin D1 is overexpressed at the mRNA and protein level in $>50 \%$ of breast cancers, in the presence or absence of gene amplification. It is one of the most commonly overexpressed proteins in breast cancer. The D-type cyclins link the extracellular signals to the cell-cycle machinery and of the three D-type cyclins, it is cyclin D1 that is predominantly associated with human tumorigenesis (8).

STATs (signal transducers and activators of transcription) may affect proliferation by regulating the expression of immediate-early genes, such as c-myc and c-fos, as well as cell cycle regulatory genes, such as the cyclins (9). The Jak/STAT pathways are activated by various growth factors and cytokines. Binding of these cytokines to their receptors activates the Jak tyrosine kinases, followed by tyrosine phosphorylation of the receptors. This leads to activation and homo- or heterodimerization of the STAT5 transcription factors, translocation into the nucleus, and activation of target genes (10). The products of the closely related ( $<90 \%$ identical) and chromosomally linked STAT5a and $-5 \mathrm{~b}$ genes are activated by a wide range of cytokines (11). Despite the amino acid identity between STAT5a and -5b of approximately 95\% and their redundant roles in regulating blood and cancer cell function, the two transcription factors also appear to have functional differences (12). For example, STAT5b is selectively important for growth hormone signaling (13), whereas STAT5a is particularly critical for prolactin-induced mammary gland differentiation $(14,15)$. Earlier studies from our own laboratory have shown that STAT5b, but not STAT5a, may be a directional mediator of the IGF-1 and cyclin D1 gene expression produced by hypoxia in human HepG2 cells (16) and breast cancer cells (17-20), respectively. In similar results, recent evidence indicates that STAT5b, but not STAT5a, has a pro-proliferate role in breast, head and neck, and prostate cancers $(17,18,21,22)$. Since STAT5b mediates breast cancer proliferation, identification of kinases that increase STAT5b activity is critical to identifying potential therapeutic targets (23).

In 2005, a distal STAT5-binding DNA region was identified that may mediate $\mathrm{GH}$ regulation of IGF-1 gene expression (24). GH stimulation of IGF-I gene expression is directly mediated by STAT5, so the cis-regulatory DNA regions involved may be the regions that contain STAT5binding sites. A region within the rat IGF-I intron 2 has recently been shown to contain two STAT5-binding sites and to mediate GH-stimulated IGF-I gene expression in the liver of rats (25), and to mediate hypoxia-stimulated IGF-1 gene expression in breast cancer cells (16). A 700-bp DNA region $75 \mathrm{~kb}$ upstream of the human IGF-I exon 1 was found to contain two closely located STAT5-binding sites that were able to bind to STAT5 proteins, thus enabling the STAT5 activation of gene expression. Binding of STAT5 to this region increased gene expression from both heterologous and homologous promoters, and was associated with increased IGF-I mRNA expression.

Oxygen limitation is central in controlling neovascularization, glucose metabolism, survival, and tumor spread. Hypoxia initiates transcription of a number of gene products that help sustain the supply of $\mathrm{O}_{2}$ to tissues and enhance cell survival during severe $\mathrm{O}_{2}$ deprivation. Hypoxia is also a stressor that alters signal transduction and gene stability. In the cancer microenvironment, hypoxia plays a significant role in determining the phenotype and progression of the tumor $(16-20,26,27)$.

In this study, we proposed that hemin inhibits IGF-1 and cyclin D1 expression via STAT5b under hypoxic conditions in invasive and metastatic MDA-MB 231 breast cancer cells. To test this hypothesis, we investigated the effects of hemin on human MDA-MB 231 breast cancer cells, viability assay, inhibition of STAT5b, the binding of STAT5b to the STAT5binding sites in the promoter of IGF-1 or cyclin D1 gene, the decrease of 700 bp IGF-I-pGL2 or cyclin D1 promoter activity, the decrease in expression of IGF-1 mRNA, and the reduction of IGF-1 mRNA or cyclin D1 and IGF-1R by STAT5b knockdown under hypoxic conditions. We found that hemin inhibits IGF-1 and cyclin D1 expression via STAT5b under hypoxic conditions in MDA-MB 231 breast cancer cells.

\section{Materials and methods}

Materials. Dulbecco's modified Eagle's medium (DMEM), RPMI-1640, 10\% fetal bovine serum (FBS) and trypsinEDTA were purchased from Gibco-BRL (Grand Island, NY, USA). L-15 medium, anti-actin antibody, insulin and EGF were obtained from Sigma Chemical Co. (St. Louis, MO, USA). Anti-STAT5b antibodies, secondary antibody (goat anti-mouse IgG-horseradish peroxidase) were obtained from Santa Cruz Biotechnology (Santa Cruz, CA, USA). The secondary antibody (horseradish peroxidase-conjugated donkey anti-rabbit $\operatorname{IgG}$ ), the enhanced chemiluminescence (ECL) detection kit and $\left[\gamma_{-}{ }^{32} \mathrm{P}\right]$ ATP were purchased from Amersham Pharmacia Biotech (Piscataway, NJ, USA). Restore $^{\mathrm{TM}}$ Western Blot Stripping Buffer and NE-PER kit were purchased from Pierce (Rockford, IL, USA). The luciferase assay substrates, reporter lysis buffer, and electrophoretic mobility shift assay (EMSA) kit were purchased from Promega Corp. (Madison, WI). FuGene 6 transfection reagent was from Roche (Basel, Switzerland), RNeasy mini kit and Qiaprep spin miniprep kit were purchased from Qiagen (Germany).

Cell culture. MDA-MB 231, human breast cancer cells, were grown to confluency in L-15 medium containing 10\% FBS and $100 \mathrm{U} / \mathrm{ml}$ penicillin. HC11, mouse mammary epithelial cells, were grown to confluency in RPMI-1640 medium containing $10 \% \mathrm{FBS}$, insulin $(5 \mu \mathrm{g} / \mathrm{ml})$, and EGF (10 $\mathrm{ng} / \mathrm{ml})$. COS-7, monkey kidney cells, and $\mathrm{CHO}$, chinese hamster ovary cells, were cultured in DMEM containing 10\% FBS, $2 \mathrm{mM}$ glutamine, and $100 \mathrm{U} / \mathrm{ml}$ penicillin and streptomycin at $37^{\circ} \mathrm{C}$ in $5 \% \mathrm{CO}_{2}$. At the start of each experiment, the cells were resuspended in the medium at a density of $2.5 \times 10^{5}$ cells $/ \mathrm{ml}$. For hypoxic conditions, the cells were placed in airtight chambers (NuAire, Plymouth, MN, USA), which were flushed with a $5 \%$ carbon dioxide $/ 95 \%$ nitrogen mixture until the oxygen concentration was $2 \%$.

Total cell lysis. MDA-MB 231 cells were treated with fac and hemin under normoxic/hypoxic conditions $\left(2 \% \mathrm{O}_{2}\right)$ for determined times. Cells were lysed on ice for $10 \mathrm{~min}$ in radioimmunoprecipitation assay (RIPA) lysis buffer containing protease and phosphatase inhibitors (50 mM Tris- $\mathrm{HCl}, \mathrm{pH} 7.5$, 
$5 \mathrm{mM}$ EDTA, $150 \mathrm{mM} \mathrm{NaCl}, 10 \mathrm{mM}$ sodium phosphate, $10 \mathrm{mM}$ sodium fluoride, $1 \mathrm{mM}$ sodium orthovanadate, $1 \%$ Triton X-100, $1 \mathrm{mM}$ phenylmethylsulfonylfluoride, and $2 \mathrm{mg} /$ $\mathrm{ml}$ leupeptin, $4 \mathrm{mg} / \mathrm{ml}$ aprotinin, $1 \mathrm{mg} / \mathrm{ml}$ pepstatin). Cells were disrupted by aspiration through a 23-gauge needle, and centrifuged at $15,000 \mathrm{rpm}$ for $10 \mathrm{~min}$ at $4^{\circ} \mathrm{C}$ to remove cellular debris. Protein concentrations were measured using the Bradford method.

Western blot analyses. Whole cell extracts (WCE) from MDA-MB 231 cells and HC11 cells were prepared by lysing cells in RIPA buffer (50 mM Tris- $\mathrm{HCl}, \mathrm{pH} 7.5,5 \mathrm{mM}$ EDTA, $150 \mathrm{mM} \mathrm{NaCl}$, and $1 \%$ Triton $\mathrm{X}-100)$ containing protease and phosphatase inhibitors ( $1 \mathrm{mM}$ PMSF, $2 \mu \mathrm{g} / \mathrm{ml}$ leupeptin, $4 \mu \mathrm{g} / \mathrm{ml}$ aprotinin, and $1 \mu \mathrm{g} / \mathrm{ml}$ pepstatin). Equal amounts of protein obtained by total lysis were subjected to $8 \%$ SDS-PAGE and electrophoretically transferred onto a nitrocellulose membrane. Western blot analyses were performed as previously described.

Expression vectors and construction of plasmid vector. The expression vectors for mouse STAT5b (pMX/STAT5b; kindly provided by Dr Koichi Ikuta, Kyoto University, Japan) were constructed as previously described. cDNA for STAT5b was inserted into the EcoRI and SalI sites of the pMX vector. Plasmid pGL2P is an enhancer-less plasmid containing SV40 promoter (Promega). 700 bp-pGL2P contains the 700-bp distal 5'-flanking region of IGF-I gene, identified as a STAT5-binding enhancer, compared with pGL2P (kindly provided by Dr Honglin Jiang, Virginia Polytechnic Institute and State University, USA). The insert from 700 bp-pGL2P was inserted into the pGL2-promoter vector at the SmaI and KpnI sites.

Electrophoretic mobility shift assay (EMSA). COS-7 cells into 35-mm culture dishes were transfected with STAT5b DNA constructs $(1 \mu \mathrm{g})$ using the FuGene 6 according to the manufacturer's instructions. STAT5b DNA binding activity was detected using an electrophoretic mobility shift assay (EMSA), in which a labeled double-stranded DNA sequence was used as a DNA probe to bind active STAT5b protein in nuclear extracts. Double-stranded oligonucleotides corresponding to the STAT5b binding site 1 (5'-TAATTCTAAGA AACT-3') and site 2 (5'-TTTTTCTTAGAAGTA-3') in the distal 5'-flanking region of the human IGF-1 gene were end-labeled with $\left[{ }^{32} \mathrm{P}\right]$ using $\mathrm{T} 4$ polynucleotide kinase and $\left[\gamma^{-32} \mathrm{P}\right]$ ATP. EMSA were performed as previously described.

Cotransfection and luciferase assay. For reporter gene assays, CHO cells were transiently co-transfected with the plasmid pGL2P or 700 bp-pGL2P construct (24) and the STAT5b expression vector. Transfected cells were washed twice with ice-cold PBS, and $150 \mu 1$ of lysis buffer was added to the wells. Lysates were then used directly to measure luciferase activity. For luciferase assays, $100 \mu 1$ of cell lysates were mixed with $350 \mu \mathrm{l}$ of assay buffer containing $25 \mathrm{mM}$ glycylglycine, $\mathrm{pH} 7.8,15 \mathrm{mM} \mathrm{MgSO}_{4}, 4$ mM EGTA, $5 \mathrm{mM}$ ATP, and $1 \mathrm{mM}$ DTT. The luciferase activity of each sample was determined by measuring luminescence for $10 \mathrm{sec}$ on a Lumat LB 9507 luminometer (EG\&G Berthold, Oak

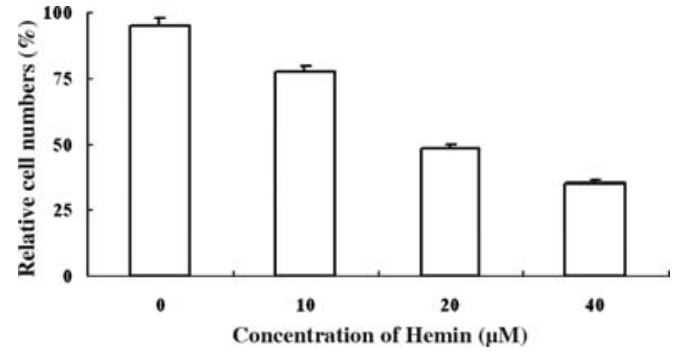

Figure 1. Effect of hemin on viability of MDA-MB 231 cells. Effect of hemin concentration on the relative number of MDA-MB-231 cells. Cells were cultured in 96-well dishes for $24 \mathrm{~h}$ and then treated with various concentrations of hemin for $6 \mathrm{~h}$. The error bars represent the standard deviation from three experiments.

Ridge, TN) after injection of $100 \mu 1$ of $1 \mathrm{mM}$ luciferine. The experiments were performed in triplicate, and similar results were obtained from at least three independent experiments.

RNA interference. The siRNA constructs for the STAT5b siRNA (pKD-STAT5b-v1) and negative control (pKDNegCon-v1) were purchased from Upstate (Lake Placid, NY). The 21-nucleotide siRNA target sequence was designed using a highly advanced search algorithm. The sequence has perfect complementarity to the STAT5b gene target, but minimal or no homology to other sequences within the genome. The siRNA target sequence was utilized to design the DNA oligonucleotides that were cloned into the $\mathrm{pKD}$ vector (Upstate, Lake Placid, NY). HC11 cells into 35-mm culture dishes were transfected with STAT5b siRNA (pKDSTAT5b-v1, $1 \mu \mathrm{g}$ ) or negative control (pKD-Negcon-v1, $1 \mu \mathrm{g}$ ) using the FuGene6 (Roche Applied Science) according to the manufacturer's instructions.

Real-time polymerase chain reaction. Total RNA from HC11 cells transfected with STAT5b siRNA or negative control was purified by an RNeasy mini kit (Qiagen). Isolated RNA samples were quantified by a spectrophotometric analysis at $260 \mathrm{~nm}$. The cDNA synthesis and the probe used for the detection of IGF-1 and B-actin from a TaqMan gene expression assay kit (Applied Biosystems Inc.). PCR was monitored in real-ime using the on ABI PRISM 7900 HT Real-time PCR System (Applied Biosystems Inc., Foster City, CA).

Data analysis and statistics. The results of the experiments are expressed as mean \pm SEM. Statistical analysis was done by t-tests or ANOVA-tests using the SAS program.

\section{Results}

Cytotoxicity of hemin in human breast cancer cells. To determine the effect of hemin on cell survival, a human breast cancer cell line (MDA-MB 231) was exposed to various concentrations of hemin $(10,20$, or $40 \mu \mathrm{M})$ for $6 \mathrm{~h}$ under hypoxic conditions. The number of hemin-treated cells in the logarithmic phase of growth was compared with that of control cells (hypoxia-treated cells). Cell growth was inhibited by $\sim 30 \%$ with $10 \mu \mathrm{M}$ hemin and by $\sim 50 \%$ with $20 \mu \mathrm{M}$ hemin (Fig. 1). Hemin treatment substantially decreased the viability of MDA-MB 231 cells in a dose-dependent manner. 
$\mathbf{A}$

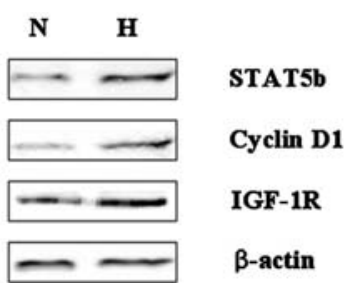

B

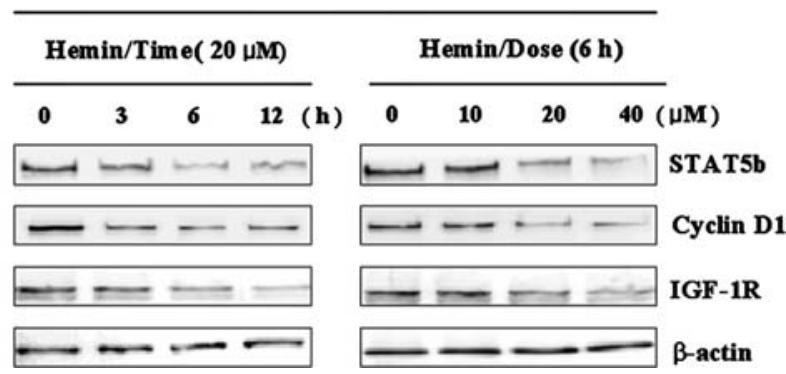

Figure 2. Over-expression from hypoxia and inhibition by hemin on STAT5b, cyclin D1 and IGF-1R proteins. (A) Expression of STAT5b, cyclin D1 and IGF-1R under normoxic $\left(20.9 \% \mathrm{O}_{2}\right)$ and hypoxic condition $\left(2 \% \mathrm{O}_{2}\right)$ in MDA-MB 231 cells. The cells were treated under hypoxic conditions $\left(2 \% \mathrm{O}_{2}\right)$ for $24 \mathrm{~h}$. (B) Time/dose course of the expression of STAT5b, cyclin D1 and IGF-1R by hemin in MDA-MB 231 cells. MDA-MB 231 cells were treated with hemin $(20 \mu \mathrm{M})$ for $0,3,6$ and $12 \mathrm{~h}$, or $0,10,20$ and $40 \mu \mathrm{M}$ of hemin for $6 \mathrm{~h}$ under hypoxic conditions, respectively. Cell lysates were separated by $8 \%$ SDS-PAGE and transferred to a nitrocellulose membrane. The membrane was blotted with the anti-STAT5b antibody, then stripped and reprobed with the anti-cyclin D1, anti-IGF-1R and anti- $\beta$-actin antibodies. Data are from one representative out of three independent experiments. $\mathrm{N}$, normoxia. $\mathrm{H}$, hypoxia.

The increase of STAT5b, cyclin DI and IGF-1R expression by hypoxia and inhibition of STAT5b, cyclin DI and IGF-1R expression by hemin in MDA-MB 231 breast cancer cells. We examined the effects of hypoxia on MDA-MB 231 cells in vitro. Hypoxia increased STAT5b, cyclin D1 and IGF-1R protein expression in MDA-MB 231 cells (Fig. 2A). We then examined effects of hemin on STAT5b, cyclin D1 and IGF-1R expressions. Hemin decreased STAT5b, cyclin D1 and IGF-1R expression of MDA-MB 231 cells under hypoxic conditions. In contrast, hemin did not decrease STAT5b, cyclin D1, or IGF-1R expression under normoxic conditions (data not shown). MDA-MB 231 cells were treated under hypoxic conditions, defined as $2 \% \mathrm{O}_{2}$, for $0,3,6$ and $12 \mathrm{~h}$ $(20 \mu \mathrm{M})$ and $0,10,20$ and $40 \mu \mathrm{M}$ of hemin. The levels of STAT5b, cyclin D1 and IGF-1R were decreased by hemin in a time- or dose-dependent manner in MDA-MB 231 cells (Fig. 2B).

The inhibition of binding of STAT5a or $-5 b$ to the STAT5binding site in the distal 5'-flanking region of IGF-1, and to the cyclin D1 promoter by hemin. The two putative STAT5 binding sites (site 1 and 2) within the 700-bp distal 5'-flanking region of the IGF-I gene can bind to STAT5b protein under the influence of GH (24). Hypoxia induces binding of nuclear proteins to STAT5 binding sites (site 1 and 2), as demonstrated by EMSA, which is consistent with its role in mediating hypoxia signals (15). These COS-7 or MDA-MB 231 cells were under normoxic condition, defined as $20 \% \mathrm{O}_{2}$ or hypoxic condition for $\left(2 \% \mathrm{O}_{2}\right) 12 \mathrm{~h}$. EMSA were performed using two oligonucleotide probes corresponding to STAT5-binding sites. Nuclear proteins from COS-7 cells transfected with STAT5 $\mathrm{a}^{\mathrm{CA}}$ or STAT5 $\mathrm{b}^{\mathrm{CA}}$ by hemin showed lower mobility complexes compared with nuclear proteins from untransfected COS-7 cells or from cells transfected with STAT5 $\mathrm{a}^{\mathrm{CA}}$ or transfected with STAT5b ${ }^{\mathrm{CA}}$ by FAC or hemin (Fig. 3A). IGF-1 binding activity at the STAT5b DNA binding site-1 was markedly decreased in hemin-treated COS-7 or MDA-MB-231 cells. In particular, hemin completely blocked hypoxia-induced STAT5b DNA-binding activity in COS-7 cells transfected with STAT5 $\mathrm{b}^{\mathrm{CA}}$ and MDA-MB 231 cells under hypoxic conditions (Fig. 3A and B) whereas, the STAT5 DNA (cyclin D1)-binding activities were markedly decreased in FAC-treated COS-7 cells under normoxia and in hemintreated COS-7 cells under hypoxia (Fig. 3C) (data not shown for binding site-2 of IGF-1).

The inhibition of 700 bp-IGF-I -pGL2 or cyclin D1 promoter activities by hemin under hypoxia. The effects of hemin on the transcriptional activation of IGF-1 was examined using a human IGF-1 promoter-luciferase construct, which contains sequences for STAT5 binding sites 1 and 2 in conjunction with a luciferase reporter. Since the 700-bp distal 5'-flanking region of the IGF-I gene containing the STAT5-binding site can mediate transactivation by STAT5, the 700-bp DNA region was inserted 5 ' to the SV40 promoter in the enhancerless pGL2P plasmid to generate plasmid 700 bp IGF-IpGL2P (24). CHO cells were transiently co-transfected with the STAT5b construct and pGL2P or 700 bp IGF-I-pGL2P. They were incubated under normoxic or hypoxic conditions over $12 \mathrm{~h}$. As shown in Fig. 4A, the relative luciferase activity of STAT5b/pGL2P under hypoxic conditions was increased over that at normoxic conditions. In particular, the relative luciferase activity (the reporter gene expression) from the STAT5b/700 bp IGF-I-pGL2P by hemin under hypoxic condition decreased compared with STAT5b/pGL2P or STAT5b/700 bp IGF-I-pGL2P by control or FAC under hypoxic conditions $(\mathrm{p}<0.01)$. As compared with the control, hemin decreased the relative luciferase activity of STAT5b/ 700 bp IGF-I-pGL2P by 70\% under hypoxic conditions, suggesting that the STAT5b protein may be a critical mediator of the STAT5b/IGF-1 pathway by hypoxia, and hemin could be a strong candidate drug.

The effects of FAC or hemin on the transcriptional activation of cyclin D1 was examined using a human cyclin D1 promoter-luciferase construct, which contains a distal cyclin D1 promoter (GAS1) sequence upstream of a luciferase reporter. CHO cells were transiently co-transfected with the cyclin D1 (GAS1) construct and STAT5b/dn or STAT5b, then cultured in serum-free media with FAC or hemin treatment under normoxic or hypoxic conditions. As shown in Fig. 4B, the relative luciferase activities of the STAT5b/cyclin D1 promoter significantly decreased after $6 \mathrm{~h}$ of hemin treatment under hypoxic conditions $(\mathrm{p}<0.01)$, whereas the relative luciferase activities of the STAT5b/dn/cyclin D1 promoter were only slightly affected by FAC or hemin under normoxic or hypoxic conditions. As compared with the control, the relative luciferase activity of STAT5b/cyclin D1 
$\mathbf{A}$
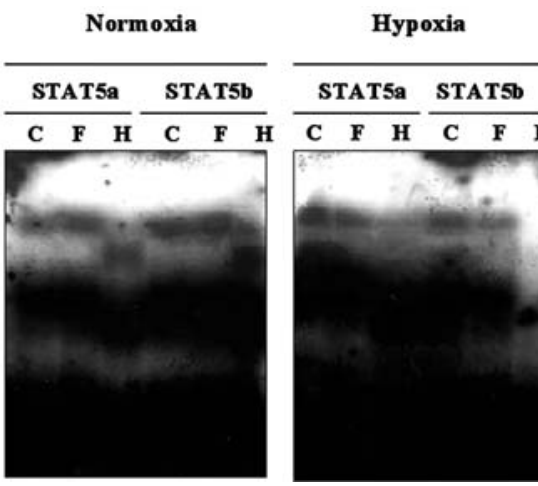

B

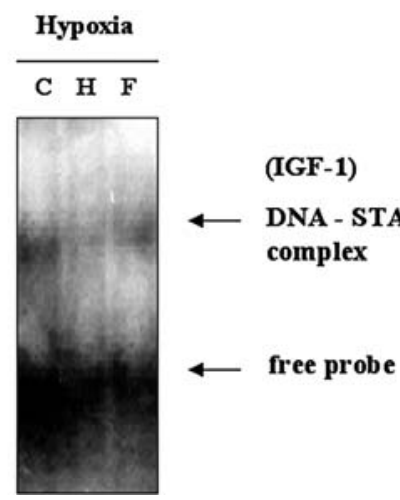

C

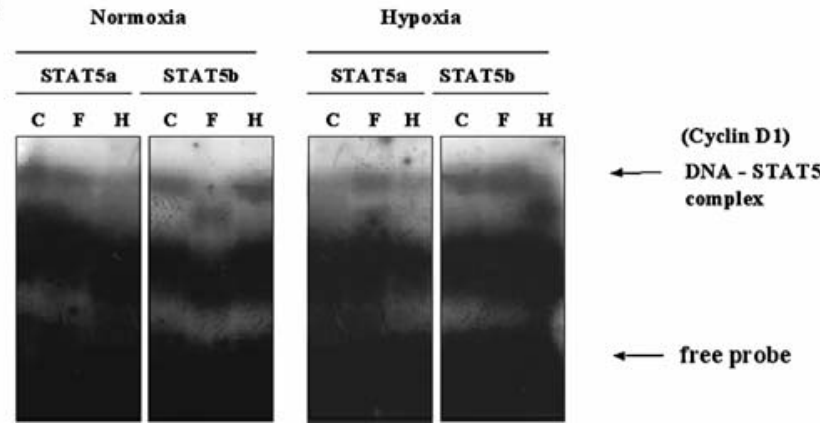

Figure 3. DNA-binding activities of STAT5 to the IGF-1 or cyclin D1. (A) Binding activities of STAT5a/b to the STAT5-binding sites (GAS-1) of the IGF-1 promoter under normoxic or hypoxic condition by FAC or hemin, as shown by EMSA. COS-7 cells were treated with $50 \mu \mathrm{M}$ of FAC and $20 \mu \mathrm{M}$ of hemin. (B) Decreasing in the binding of STAT5b to the IGF-1 under hypoxic condition by hemin or FAC in MDA-MB 231 cells. (C) Binding activities of STAT5a/b to the cyclin D1-GAS1 site under normoxic or hypoxic condition by FAC or hemin. COS-7 cells were treated with $50 \mu \mathrm{M}$ of FAC and $20 \mu \mathrm{M}$ of hemin. Nuclear extracts were prepared and then were incubated with a $\left.{ }^{32} \mathrm{P}\right]$-labeled probe specific for the STAT5-binding sites of IGF-1 or cyclin D1. The resulting complexes were electrophoresed in $6 \%$ non-denaturing gels. C, control. F, FAC. H, hemin.

(6 h) decreased $70 \%$ with hemin treatment under hypoxic conditions. These results suggest that the STAT5b protein may be a critical mediator of the STAT5b/cyclin D1 pathway by hemin under hypoxia.

The decrease in IGF-1 mRNA expression due to hemin. Hemin was examined for its effects on IGF-1 gene expression under normoxic and hypoxic conditions as follows. mRNA was isolated from HC11 cells, which were incubated under normoxic conditions and hypoxic conditions $\left(2 \% \mathrm{O}_{2}\right)$, and subjected to real-time PCR for IGF-1 gene amplification.
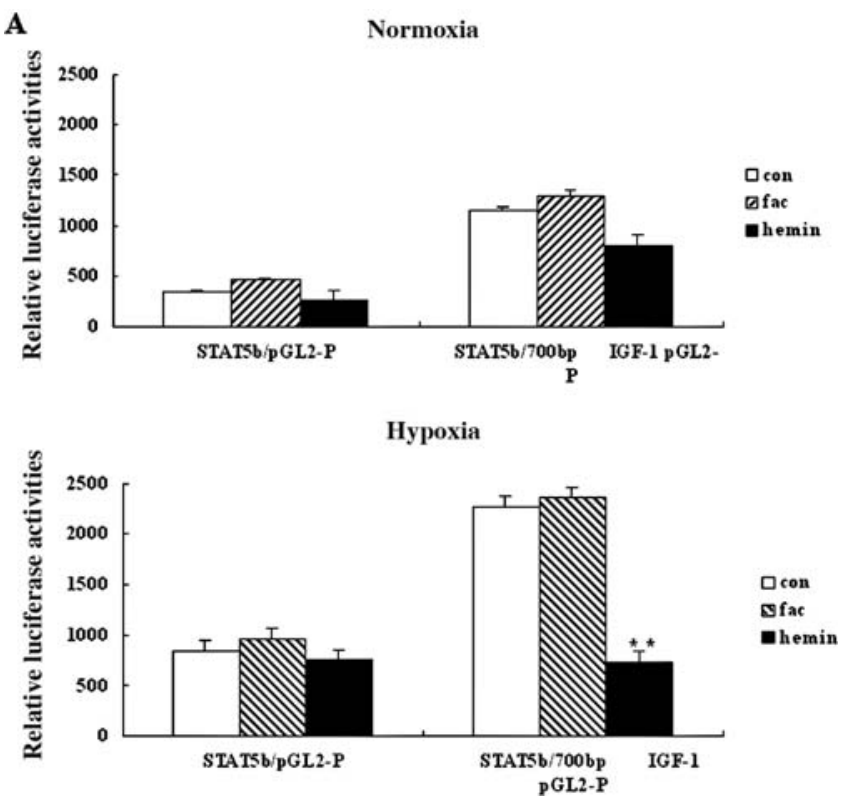

B
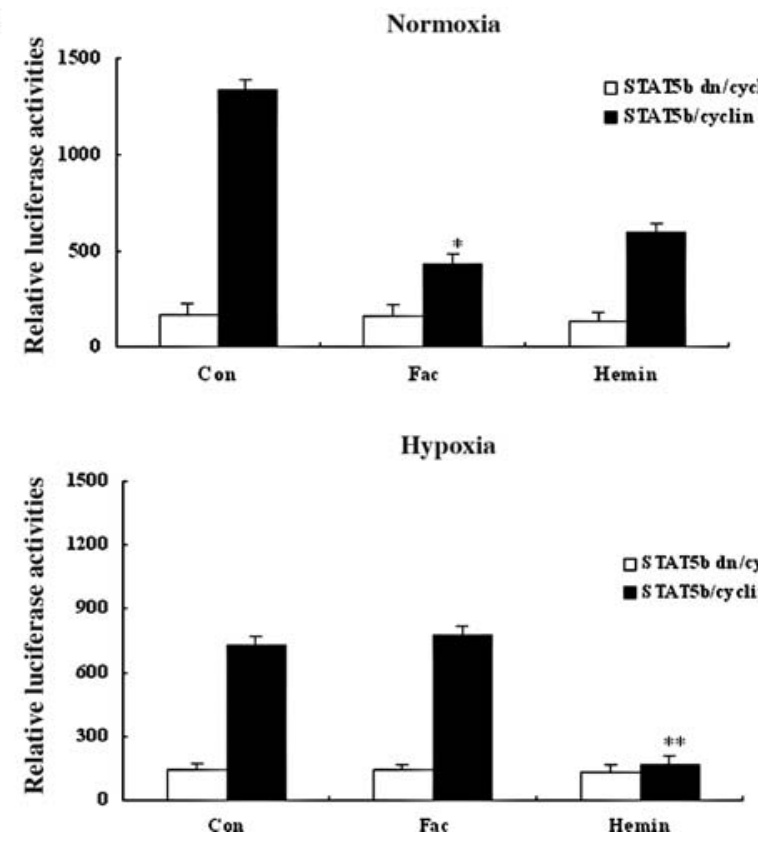

Figure 4. Inhibition of the STAT5b $\mathrm{b}^{\mathrm{CA}} / 700-\mathrm{bp} \mathrm{IGF-1-pGL2} \mathrm{promoter} \mathrm{and}$ STAT5b/cyclin D1 promoter by FAC and hemin under normoxia $(20.9 \%$ $\left.\mathrm{O}_{2}\right)$ or hypoxia $\left(2 \% \mathrm{O}_{2}\right)$ of $\mathrm{CHO}$ cells. $\mathrm{CHO}$ cells were transiently cotransfected with an IGF-1 or cyclin D1 luciferase reporter and STAT5b genes, and then cultured in serum-free media with FAC $(50 \mu \mathrm{M})$ or hemin $(20 \mu \mathrm{M})$. Cell lysates were assayed for luciferase activity. Data represent means of at least three separate experiments, means \pm SEM. (A) The 700-bp IGF-1-pGL2P is the 700-bp distal 5'-flanking region including the STAT5-binding sites of the IGF-I gene. Asterisks indicate a statistically significant decrease by ANOVA tests $\left({ }^{*} \mathrm{p}<0.05\right)$ in hemin-treated promoter activity compared with other controls under hypoxic conditions. (B) Inhibition of STAT5b/cyclin D1 promoter by FAC and hemin. Asterisks indicate a statistically significant decrease by ANOVA tests in FAC-treated promoter activity compared with others under normoxic conditions $\left({ }^{*} \mathrm{p}<0.05\right)$, and hemin-treated promoter activity compared with other controls under hypoxic conditions $\left({ }^{* *} \mathrm{p}<0.01\right)$. Con, control.

Real-time PCR was performed using an ABI 7900 HT real-time PCR system according to the TaqMan Gene Expression Assay method. The expression levels of IGF-1 

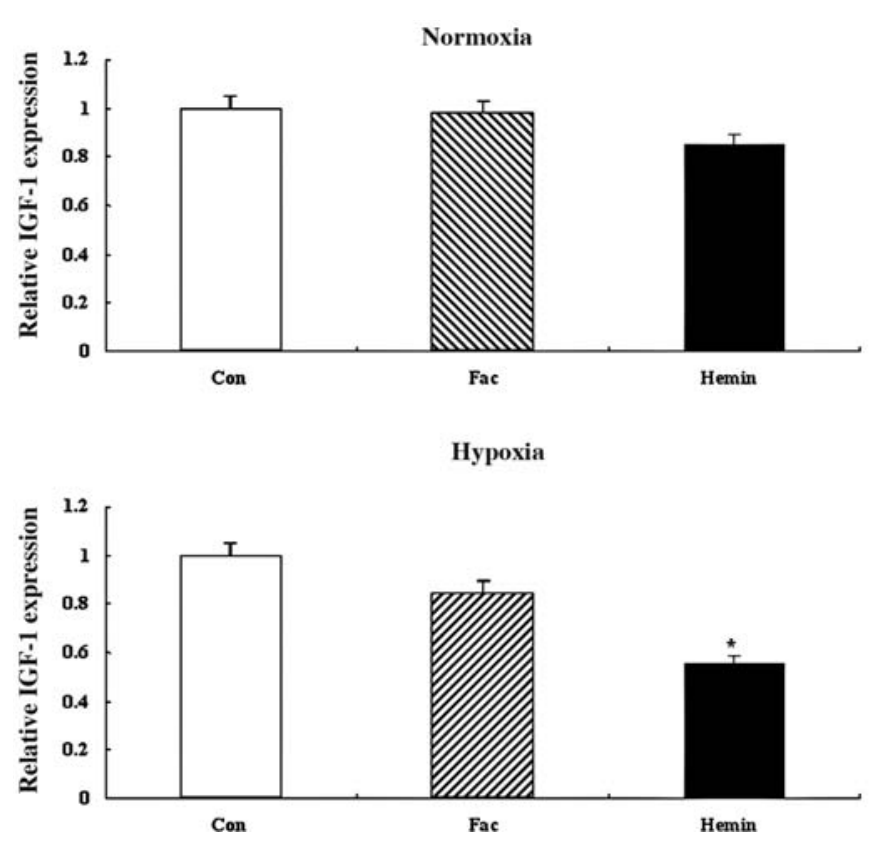

Figure 5. Real-time PCR results of IGF-1 mRNA by FAC or hemin under normoxic condition $\left(20.9 \% \mathrm{O}_{2}\right)$ or hypoxic condition $\left(2 \% \mathrm{O}_{2}\right)$ of $\mathrm{HC} 11$ cells. The real-time PCR was performed using TaqMan Gene Expression Assays for human IGF-I and B-actin mRNAs from ABI on ABI 7900 HT Real-time PCR System. The values are means \pm SE $(n=3)$ after normalization to $B$-actin mRNA levels (internal control). Asterisks indicate a statistically significant decrease by Student's t-test $\left({ }^{*} \mathrm{p}<0.05\right)$ under hypoxic conditions as compared with other controls. Con, control.

gene were obtained by conducting the above procedure 3 times, and were normalized against the level of $\beta$-actin mRNAs. The results are graphed in Fig. 5, where asterisks show statistically significant decreases $(>50 \%)$ in IGF-1 gene expression by hemin under hypoxic conditions as compared with a hypoxic control or FAC, as determined using an ANOVA test $(\mathrm{p}<0.05)$. However, they were unaffected under normoxic conditions.

Reduction of cyclin DI and IGF-1R protein or IGF-1 mRNA expression by STAT5b knock-down. An examination was made of the inhibition of a small interference RNA (si-STAT5b) against STAT5b, cyclin D1, and IGF-1R proteins or IGF-1 gene expression (STAT5b knock-down by si-STAT5b). In this regard, MDA-MB 231 cells were incubated with control or pKD-NegCon (mock) and interference RNA siSTAT5b (pKD-siSTAT5b) for $24 \mathrm{~h}$ in a normal atmosphere and a $2 \% \mathrm{O}_{2}$ atmosphere. After being harvested, the cells were subjected to immunoblotting against STAT5b, cyclin D1, IGF-1R and $B$-actin to analyze the expression levels thereof (Fig. 6A). Treatment of MDA-MB 231 cells with siRNASTAT5b resulted in efficient and specific inhibition of STAT5b transcripts. The siRNA-STAT5b showed cyclin D1 and IGF-1R expression under hypoxia in MDA-MB 231 cells that was significantly high compared with normoxia (Fig. 6A). As seen in Fig. 6B, siRNA-STAT5b acted to decrease IGF-1 gene expression. Under hypoxic conditions, the HC11 cells transformed with pKD-siSTAT5b underwent a $70 \%$ decrease in IGF-1 mRNA level while the control was not affected at all. The decreased level of IGF-1 mRNA was
A
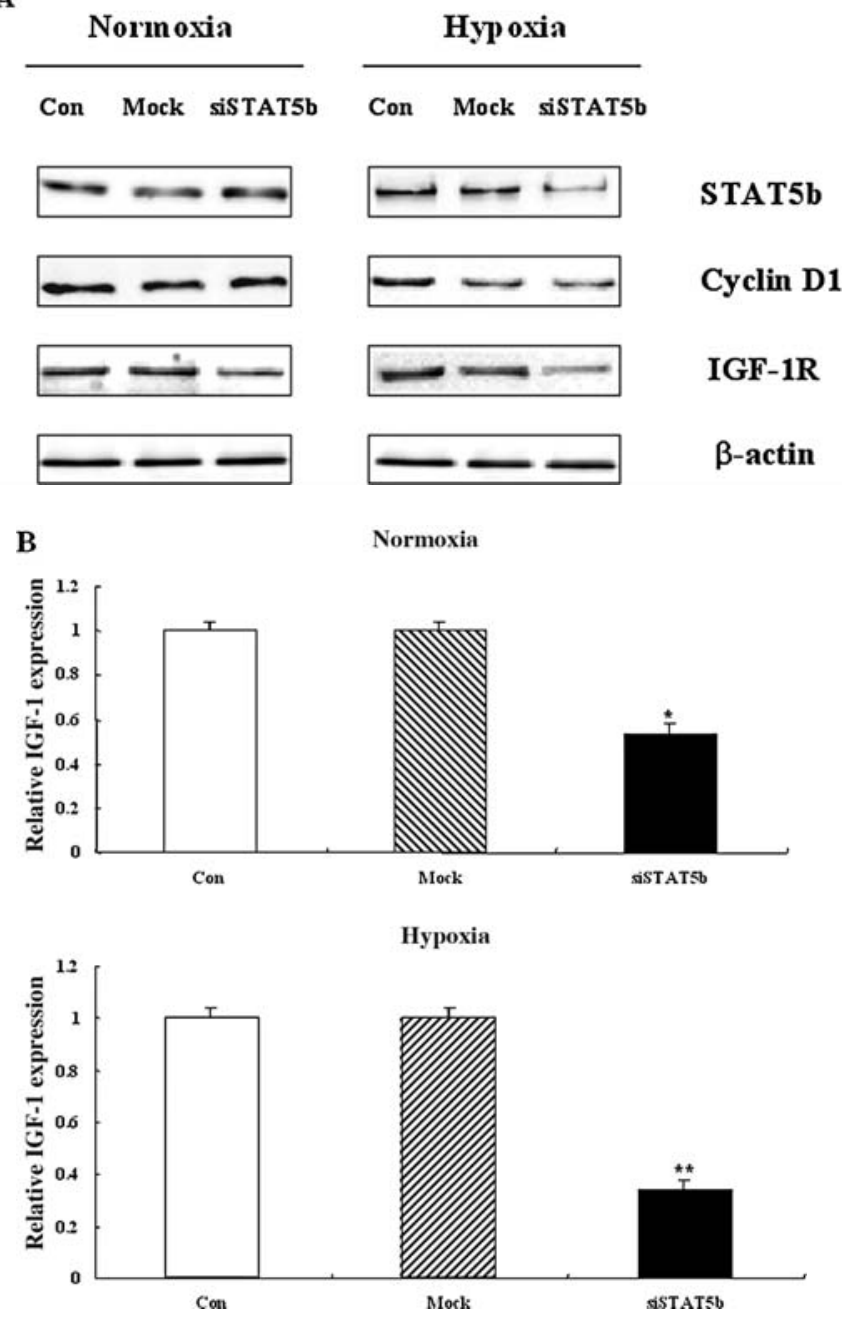

Figure 6. Hypoxia-stimulated cyclin D1 and IGF-1R protein or IGF-1 gene expression require STAT5b. (A) The cyclin D1 and IGF-1R expression require STAT5b. MDA-MB 231 cells were treated with mock (pKD-NegCon) or siSTAT5b (pKD-siSTAT5b) under normoxic or hypoxic conditions. Cells were harvested after $24 \mathrm{~h}$ for assay of STAT5b, cyclin D1, IGF-1R and B-actin by immunoblotting. Under hypoxic condition $\left(2 \% \mathrm{O}_{2}, 24 \mathrm{~h}\right)$ siSTAT5b (pKDsiSTAT5b) transfection of MDA-MB 231 cells showed a $>70 \%$ reduction of STAT5b transcript levels, whereas mock (pKD-NegCon) was unaffected. (B) Treatment with siRNA-STAT5b reduced expression of target gene IGF-1 in HC11 cells. Real-time PCR also revealed a significant reduction (decrease by $70 \%$ ) of IGF-1 transcripts under hypoxic conditions ${ }^{* *} \mathrm{p}<0.01$ ). Con, control. siSTAT5b, siRNA-STAT5b.

also confirmed through real-time PCR. Thus, IGF-1 is a target gene of hypoxia signal transduction, and regulation of IGF-1 mRNA level is likely to be the result of hypoxia activation of STAT5b.

\section{Discussion}

We have reported that STAT5b mediates and regulates the transactivation of cyclin D1 by hypoxia stimulation in breast cancer cells, suggesting a novel biological role for STAT5b in the regulation of hypoxia-signaling pathways (17-19), and we recently reported that hypoxia activates IGF-1 expression through STAT5b in human HepG2 cells (16), and enhancement of hypoxia-induced apoptosis of human breast cancer cells via STAT5b by momilactone B (20). 
STAT5 proteins activate the expression of the cyclin D1 gene through the recognition of a conserved element in the promoter $(28,29)$. As one of the target genes activated by the STAT cascade, cyclin D1 is probably an important mediator of the STAT-dependent growth of hematopoietic cells. However, the exact role of this protein in this signaling pathway is yet to be determined. It has been postulated that the activated form of STAT5 due to hypoxia may contribute to one level of control by modulation of the transcriptional activity of the cyclin D1 promoter. However, differences in transcriptional activities of STAT5a and $-5 \mathrm{~b}$ induced by hypoxia have been shown. It is known that ligand-dependent and -independent signal transduction pathways may differentially regulate STAT5a and -5 b nuclear translocation, and therefore have the potential to differentially regulate STAT5-dependent gene expression (30).

Novel functions of STAT5b, a new target of breast tumor kinase/protein tyrosine kinase 6 have been reported (23), and another function of STAT5b in breast cancer cell migration was demonstrated (31). The authors suggested that STAT5b not only functions in the initiation of tumorigenesis, through its pro-proliferative and pro-survival signaling, but may also promote tumor progression by mediating migration, using two aggressive, highly migratory breast cancer cell lines (MDA-MB 231 and BT-549).

Insulin-like growth factor 1 (IGF-1) appears to play a crucial role in cell division, proliferation, growth, and metastasis of most solid cancers, such as breast cancer and prostate cancer. During angiogenesis, a hypoxic condition is created around solid cancer cells, stimulating oncogenes and oncoproteins of the cells. Thus, solid cancer cells become more malignant and undergo cell division, proliferation, growth, and metastasis, for which IGF is responsible. IGF-1 plays an important role in tumorigenesis and tumor progression in a variety of tumors and is a potent mitogen in cancer cells $(32,33)$. However, the mechanism of regulating IGF-1 expression by cytokines, growth hormone, or hypoxia in humans has been difficult to study, in part because of the lack of an appropriate cell model (13). Based on recent findings that $\mathrm{GH}$ regulation of IGF-I gene expression in the liver depends on STAT5b $(34,35)$ and STAT5a $(36,37)$, Wang and Jiang (24) screened the entire human IGF-I gene as well as an extensive 5-flanking region for sequences that can function as STAT5-binding enhancers.

Insulin-like growth factor 1 receptor (IGF-1R) and cyclin D1 are the key regulators of cell proliferation that are overexpressed in most breast cancers (38). In particular, levels of IGF-1 has been associated with breast cancer risk among premenopausal women (39). As a recent trend in breast cancer among younger women in the United States, the annual percentage change in the incidence of invasive breast cancers decreased modestly among older women, but increased among younger ( $<40$ years) white women. But the mechanisms that influence the incidence of breast cancer in premenopausal women are less well understood (7).

There is a needed to prove that IGF-I has a role in human malignancy. Again, using estrogen and ER $\alpha$ as a model, two areas need to be further explored. First, a method to block IGF action must be shown to be effective as a cancer therapy. For estrogen action, ovariectomy in pre-menopausal women demonstrated that lowering circulating estrogen levels had a therapeutic benefit in patients with advanced cancer. The development of tamoxifen unequivocally showed that ER $\alpha$ is a key target in breast cancer, and eventually led to the observation that administration of tamoxifen reduced breast cancer risk in healthy women. Second, it needs to be proven that raising levels of IGF-I enhances cancer risk. The effect of concomitant increases in IGFBP-3 also needs to be evaluated (40).

Hemin (iron-protoporphyrin IX), the $\mathrm{Fe}^{3+}$ oxidation product of heme, is a natural agent that promotes growth of hematopoietic cells and induces erythroid differentiation in human leukemias, like K-562 and HEL cells. Hemin acts as a feedback inhibitor to ALA synthase. Hemin also inhibits transport of ALA synthase from the cytosol (its site of synthesis) into the mitochondria (its site of action) as well as repressing synthesis of the enzyme. Hemin has been shown to inhibit apoptosis in human monocytes (41) despite caspase 3 upregulation. These findings taken together suggest that heme is a determinant of life and death in renal tubular epithelial (42) and other cell types like hematopoietic and liver cells. Another interesting observation about hemin that has attracted worldwide attention from a clinical perspective is its unique ability to selectively inhibit the transcription of embryonic and fetal, but not of adult, globin gene in K-562 cells $(43,44)$.

Some investigators suggested that hemin can be therapeutically valuable agent in the treatment of $\beta^{\circ}$-thalassemia because it selectively promotes $\mathrm{HbF}(\alpha 2 \gamma 2)$ synthesis. Administration of hemin arginate in thalassemic patients was found to elevate hemoglobin content by 3 -fold without causing any serious adverse reactions (45). In addition to thalassemia, hemin arginate has been used as a drug of choice to treat patients suffering from acute porphyries with severe neurological manifestations. Also, hemin is a potentially cytotoxic compound; several studies have demonstrated the ability of hemin to initiate lipid peroxidation (46) and to cause the degradation of protein (47) and DNA (48). It has also been shown that exposure to hemin is capable of enhancing the sensitivity of endothelial cells to oxidative injury (49). Additionally, hemin is both a potent inducer of and substrate for the inducible isoform of heme oxygenase (HO-1) (50). While Tsiftsoglou et al (1) have observed that hemin protected human normal and leukemic hematopoietic cells from cytotoxicity induced by anthracyclines, in particular adriamycin. However, it has not been made clear how hemin protects cells from cytotoxicity induced by antineoplastic agents, although recently it has been shown that hemin activates expression of HO-1 (HSP32) in order to protect cells against oxidative stress $(51,52)$. Hemin has also been shown to protect several other cell types (hepatocytes, gastric cancer cells, renal tubular epithelial cells) from oxidative stress induced by $\mathrm{H}_{2} \mathrm{O}_{2}$, cisplatin, tumor necrosis factor- $\alpha$ (TNF- $\alpha$ ), and even tetrachloride $\left(\mathrm{CCl}_{4}\right)$, via activation of the HO-1 gene (50,53-57).

In this study, we hypothesized that hemin could suppress the hypoxia-induced cyclin D1 and IGF-1 expression of metastatic breast cancer cells. To test this hypothesis, we generated stable cyclin D1- and IGF-1R-expressing cells of the highly invasive/metastatic MDA-MB 231 breast cancer 
cells and mammary epithelial cells (HC11), and tested their levels under hypoxia compared with their control counterparts. Hemin substantially decreased the viability of MDA-MB 231 cells in a dose-dependent manner at $20 \mu \mathrm{M}$ of hemin, as an $\mathrm{IC}_{50}$ (Fig. 1). We also found that proteins of STAT5b, cyclin D1, and IGF-1R were more overexpressed under hypoxic conditions than under normoxic conditions (Fig. 2A), and hemin suppressed hypoxia-induced increases in STAT5b, cyclin D1 and IGF-1R protein levels (Fig. 2B). The STAT5b DNA-binding activity to IGF-1 or cyclin D1 promoters were markedly decreased in hemin-treated COS-7 or MDA-MB 231 cells under hypoxia (Fig. 3), and the IGF-1 or cyclin D1 promoter activities were significantly decreased by hemin under hypoxia of MDA-MB 231 cells (Fig. 4). Moreover, IGF-1 mRNA expression by hemin decreased by $40 \%$ under hypoxic conditions (Fig. 5). Finally, we found that hypoxia-stimulated cyclin D1 and IGF-1R or IGF-1 expression requires STAT5b (Fig. 6).

This finding applies to the IGF-I pathway and cancer. Several studies have shown that IGF-I activation of its receptor stimulates ER $\alpha$ function. In ER $\alpha$ expressing breast cancer cells, IGF-I and estradiol act synergistically to enhance growth (58-60). Multiple pathways may be responsible for estrogen/IGF-I synergy, but enhancement of $\mathrm{ER} \alpha$ transcriptional activity by IGF-I signaling is one likely mechanism $(61,62)$. Thus, IGF-I has a role in human malignancy. It seems likely that within a few years, the relationship of IGF-I to human cancer will be established. These findings are valuable in understanding the role of hemin-induced inhibition of cyclin D1 and IGF-1 expression under hypoxic condition of ER $\alpha$-negative breast cancer cells, as a novel strategy for preventing ER-negative breast cancer. In addition, hemin can be a therapeutically valuable agent, exerting its activities via the JAK2/STAT5b pathway, thus lowering the incidence of more aggressive ER-negative breast cancers, which are associated with a poorer prognosis compared to ER-positive cancer.

\section{Acknowledgements}

We especially thank Dr Honglin Jiang at Virginia Polytechnic Institute and State University, USA, for the kind provision of the IGF-1/700-bp pGL2 plasmid. This work was supported by the Ministry of Commerce, Industry and Energy through the Bio-Food and Drug Research Center at Konkuk University, Chungju, Korea.

\section{References}

1. Tsiftsoglou AS, Tsamadou AI and Papadopoulou LC: Heme as key regulator of major mammalian cellular functions: molecular, cellular, and pharmacological aspects. Pharmacol Ther 111: 327-345, 2006.

2. Jones JI and Clemmons DR: Insulin-like growth factors and their binding proteins. Biological actions. Endocr Rev 16: 3-34, 1995.

3. Duan C: Specifying the cellular responses to IGF signals: roles of IGF-binding proteins. J Endocrinol 175: 41-54, 2002.

4. Martin MB and Stoica A: Insulin-like growth factor-1 and estrogen interactions in breast cancer. J Nutr 132: S3799-S3801, 2002 .

5. Daughaday WH and Rotwein P: Insulin-like growth factors I and II. Peptide, messenger ribonucleic acid and gene structure, serum and tissue concentrations. Endocr Rev 10: 68-91, 1989.
6. Coskun U, Günel N, Sancak B, Günel U, Onuk E, Bayram O, Yílmaz E, Candan S and Ozkan S: Significance of serum vascular endothelial growth factor, insulin-like growth factor-I levels and nitric oxide activity in breast cancer patients. Breast 12: 104-110, 2003

7. Gaber K: IGF-1: Old growth factor shines as new drug target. J Natl Cancer Inst 97: 790-792, 2005.

8. Yu Q, Geng Y and Sicinski P: Specific protection against breast cancers by cyclin D1 ablation. Nature 411: 1017-1021, 2001.

9. Bowman T, Garcia R, Turkson J and Jove R: STATs in oncogenesis. Oncogene 19: 2474-2488, 2000.

10. Bienvenu F, Gascan H and Coqueret O: Cyclin D1 represses STAT3 activation through a Cdk4-independent mechanism. J Biol Chem 276: 16840-16847, 2001.

11. O'Shea JJ, Gadina M and Schreiber RD: Cytokine signaling in 2002: new surprises in the Jak/Stat pathway. Cell 109: S121-S131, 2002.

12. Grimley PM, Dong F and Rui H: Stat5a and Stat5b: fraternal twins of signal transduction and transcriptional activation. Cytokine Growth Factor Rev 10: 131-157, 1999.

13. Udy GB, Towers RP, Snell RG, Wilkins RJ, Park SH, Ram PA, Waxman DJ and Davey HW: Requirement of STAT5b for sexual dimorphism of body growth rates and liver gene expression. Proc Natl Acad Sci USA 94: 7239-7244, 1997.

14. Liu X, Robinson GW, Wagner KU, Garrett L, Wynshaw-Boris A and Hennighausen L: Stat5a is mandatory for adult mammary gland development and lactogenesis. Genes Dev 11: 179-186, 1997.

15. Yamashita H, Nevalainen MT, Xu J, Le Baron MJ, Wagner KU, Erwin RA, Harmon JM, Hennighausen L, Kirken RA and Rui H: Role of serine phosphorylation of Stat5a in prolactinstimulated ß-casein gene expression. Mol Cell Endocrinol 183: 151-163, 2001.

16. Joung YH, Lee MY, Lim EJ, Kim MS, Hwang TS, Kim SY, Ye SK, Lee JD, Park TK, Woo YS, Chung IM and Yang YM: Hypoxia activates the IGF-1 expression through STAT5b in human HepG2 cells. Biochem Biophys Res Commun 358: 733-738, 2007.

17. Joung YH, Park JH, Park T, Lee CS, Kim OH, Ye SK, Yang UM, Lee KJ and Yang YM: Hypoxia activated signal transducers and activators of transcription 5 (STAT5) and increase its binding activity to the GAS element in mammary epithelial cells. Exp Mol Med 35: 350-357, 2003.

18. Joung YH, Lim EJ, Lee MY, Park JH, Ye SK, Park EU, Kim SY, Zhang Z, Lee KJ, Park DK, Park T, Moon WK and Yang YM: Hypoxia activates the cyclin D1 promoter via the Jak2/STAT5b pathway in breast cancer cells. Exp Mol Med 37: 353-364, 2005.

19. Lee MY, Joung YH, Lim EJ, Park JH, Ye SK, Park T, Zhang Z, Park DK, Lee KJ and Yang YM: Phosphorylation and activation of STAT proteins by hypoxia in breast cancer cells. Breast 15: 187-195, 2006

20. Joung YH, Lim EJ, Kim MS, Lim SD, Yoon SY, Lim YC, Yoo YB, Ye SK, Park T, Chung IM, Bae KY and Yang YM: Enhancement of hypoxia-induced apoptosis of human breast cancer cells via STAT5b by momilactone B. Int J Oncol 33: 477-484, 2008.

21. Bichell DP, Kikuchi K and Rotwein P: Growth hormone rapidly activates insulin-like growth factor I gene transcription in vivo. Mol Endocrinol 6: 1899-1908, 1992.

22. Onishi M, Kinoshita S, Morikawa Y, Shibuya A, Phillips J, Lanier LL, Gorman DM, Nolan GP, Miyajima A and Kitamura T: Applications of retrovirus-mediated expression cloning. Exp Hematol 24: 324-329, 1996.

23. Weaver AM and Silva CM: Signal transducer and activator of transcription 5b (STAT5b): a new target of breast tumor kinase/ protein tyrosine kinase 6 (Brk/PTK6). Breast Cancer Res 9: R79, 2007.

24. Wang $\mathrm{Y}$ and Jiang $\mathrm{H}$ : Identification of a distal STAT5-binding DNA region that may mediate growth hormone regulation of insulin-like growth factor-I gene expression. J Biol Chem 280: 10955-10963, 2005.

25. Woelfle J, Chia DJ and Rotwein P: Mechanisms of growth hormone $(\mathrm{GH})$ action. Identification of conserved Stat5 binding sites that mediate $\mathrm{GH}$-induced insulin-like growth factor-I gene activation. J Biol Chem 278: 51261-51266, 2003.

26. Pouyssegur J, Dayan F and Mazure NM: Hypoxia signaling in cancer and approaches to enforce tumour regression. Nature 441: 437-443, 2006.

27. Bando H, Toi M, Kitada K and Koike M: Genes commonly upregulated by hypoxia in human breast cancer cells MCF-7 and MDA-MB-231. Biomed Pharmacother 57: 333-340, 2003. 
28. Bromberg JF, Wrzeszczynska MH, Devgan G, Zhao Y, Pestell RG, Albanese C and Darnell JE Jr: Stat3 as an oncogene. Cell 98: 295-303, 1999.

29. Matsumura I, Kitamura T, Wakao H, Tanaka H, Hashimoto K, Albanese C, Downward J, Restell RG and Kanakura Y: Transcriptioal regulation of the cyclin D1 promoter by STAT5: its involvement in cytokine-dependent growth of hematopoietic cells. EMBO J 18: 1367-1377, 1999.

30. Kazansky AV, Kabotyanski EB, Wyszomierski SL, Mancini MA and Rosen JM: Differential effects of prolactin and src/abl kinases on the nuclear translocation of STAT5B and STAT5A. J Biol Chem 274: 22484-22492, 1999.

31. Bernaciak TM, Zareno J, Parsons JT and Silva CM: A novel role for signal transducer and activator of transcription $5 \mathrm{~b}$ (STAT5b) in beta1-integrin-mediated human breast cancer cell migration. Breast Cancer Res 11: R52, 2009.

32. Macaulay VM: Insulin-like growth factors and cancer. Br J Cancer 65: 311-320, 1992.

33. Hwang PH, Kim SY, Lee JC, Kim SJ, Yi HK and Lee DY: PTEN/MMAC1 enhances the growth inhibition by anticancer drugs with downregulation of IGF-II expression in gastric cancer cells. Exp Mol Med 37: 391-398, 2005.

34. Teglund S, McKay C, Schuetz E, van Deursen JM, Stravopodis D, Wang D, Brown M, Bodner S, Grosveld G and Ihle JN: Stat5a and Stat5b proteins have essential and non-essential, or redundant, roles in cytokine responses. Cell 93: 841-850, 1998.

35. Ariyoshi K, Nosaka T, Yamada K, Onishi M, Oka Y, Miyajima A and Kitamura T: Constitutive activation of STAT5 by a point mutation in the SH2 domain. J Biol Chem 275: 24407-24413, 2000.

36. Davey HW, Xie T, McLachlan MJ, Wilkins RJ, Waxman DJ and Grattan DR: STAT5b is required for GH-induced liver IGF-1 gene expression. Endocrinology 142: 3836-3842, 2001.

37. Park JH, Lee HY, Roh SC, Kim HY and Yang YM: Screening of differentially expressed genes by desferri-oxamine or ferric ammonium citrate treatment in HepG2 Cells. J Biochem Mol Biol 33: 396-401, 2000.

38. Tian X, Aruva MR, Zhang K, Shanthly N, Cardi CA, Thakur ML and Wickstrom E: PET imaging of CCND1 mRNA in human MCF7 estrogen receptor positive breast cancer xenografts with oncogene-specific [64Cu]chelator-peptide nucleic acid-IGF1 analog radiohybridization probes. J Nucl Med 48: 1699-1707, 2007.

39. Diorio C, Brisson J, Berube S and Pollak M: Intact and total insulin-like growth factor-binding protein-3 (IGFBP-3) levels in relation to breast cancer risk factors: a cross-sectional study. Breast Cancer Res 10: R42, 2008.

40. Ibrahim YH and Yee D: Insulin-like growth factor-1 and cancer risk. Growth Horm IGF Res 14: 261-269, 2004.

41. Lang D, Reuter S, Buzescu T, August C and Heidenreich S: Hemeinduced heme oxygenase-1 (HO-1) in human monocytes inhibits apoptosis despite caspase-3 up-regulation. Int Immunol 17: 155-165, 2005

42. Gonzalez-Michaca L, Farrugia G, Croatt AJ, Alam J and Nath KA: Heme: a determinant of life and death in renal tubular epithelial cells. Am J Physiol Renal Physiol 286: F370-F377, 2004.

43. Rutherford TR, Clegg JB and Weatherall DJ: K562 human leukaemic cells synthesize embryonic hemoglobin in response to haemin. Nature 280: 164-165, 1979.

44. Benz EJ Jr, Murnane MJ, Tonkonow BL, Berman BW, Mazur EM, Cavallesco C, Jenko T, Snyder EL, Forget BG and Hoffman R: Embryonic-fetal erythroid characteristics of a human leukemic cell line. Proc Natl Acad Sci USA 77: 3509-3513, 1980.
45. Rund D, Fibach E., Goldfarb A, Friedberg A and Rachmilewitz E: Heme arginate therapy for beta thalassemia: in vitro versus in vivo effects. Acta Haematol 100: 82-84, 1998.

46. Gutteridge JM and Smith A: Antioxidant protection by haemopexin of haem-stimulated lipid peroxidation. Biochem J 256: 861-865, 1988 .

47. Aft RL and Mueller GC: Hemin-mediated oxidative degradation of proteins. J Biol Chem 259: 301-305, 1984.

48. Suliman HB, Carraway MS, Velsor LW, Day BJ, Ghio AJ and Piantadosi CA: Rapid mtDNA deletion by oxidants in rat liver mitochondria after hemin exposure. Free Radic Biol Med 32: 246-256, 2002.

49. Balla J, Jacob HS, Balla G, Nath K, Eaton JW and Vercellotti GM: Endothelial-cell heme uptake from heme proteins: induction of sensitization and desensitization to oxidant damage. Proc Natl Acad Sci USA 90: 9285-9289, 1993.

50. Wilson SJ and Keenan AK: Role of hemin in the modulation of $\mathrm{H}_{2} \mathrm{O}_{2}$-mediated endothelial cell injury. Vascul Pharmacol 40: 109-118, 2003

51. Yamada N, Yamaya M, Okinaga S, Lie R, Suzuki T, Nakayama K, Takeda A, Yamaguchi T, Itoyama Y, Sekizawa K and Sasaki H: Protective effects of heme oxygenase-1 against oxidant-induced injury in the cultured human tracheal epithelium. Am J Respir Cell Mol Biol 21: 428-435, 1999.

52. Clark JE, Foresti R, Green CJ and Motterlini R: Dynamics of haem oxygenase-1 expression and bilirubin production in cellular protection against oxidative stress. Biochem J 348: 615-619, 2000.

53. Ghattas MH, Chuang LT, Kappas A and Abraham NG: Protective effect of HO-1 against oxidative stress in human hepatoma cell line (HepG2) is independent of telomerase enzyme activity. Int J Biochem Cell Biol 34: 1619-1628, 2002.

54. Schaaf GJ, Maas RF, De Groene EM and Fink-Gremmels J: Management of oxidative stress by heme oxygenase- 1 in cisplatininduced toxicity in renal tubular cells. Free Radic Res 36: 835-843, 2002

55. Amon M, Menger MD and Vollmar B: Heme oxygenase and nitric oxide synthase mediate cooling-associated protection against TNF-alpha-induced microcirculatory dysfunction and apoptotic cell death. FASEB J 17: 175-185, 2003

56. Nakahira K, Takahashi T, Shimizu H, Maeshima K, Uehara K, Fujii H, Nakatsuka H, Yokoyama M, Akagi R and Morita K: Protective role of heme oxygenase-1 induction in carbon tetrachloride-induced hepatotoxicity. Biochem Pharmacol 66: 1091-1105, 2003

57. Kim YS, Zhuang H, Koehler RC and Dore S: Distinct protective mechanisms of HO-1 and HO-2 against hydroperoxide-induced cytotoxicity. Free Radic Biol Med 38: 85-92, 2005.

58. Carroll VA and Ashcroft M: Role of hypoxia-inducible factor (HIF)-1alpha versus HIF-2alpha in the regulation of HIF target genes in response to hypoxia, insulin-like growth factor-I, or loss of von Hippel-Lindau function: implications for targeting the HIF pathway. Cancer Res 66: 6264-6270, 2006.

59. Cui Y, Vogt S, Olson N, Glass AG and Rohan TE: Levels of zinc, selenium, calcium, and iron in benign breast tissue and risk of subsequent breast cancer. Cancer Epidemiol Biomarkers Prev 16: 1682-1685, 2007.

60. Buitenhuis M, Coffer PJ and Koenderman L: Signal transducer and activator of transcription 5 (STAT5). Int J Biochem Cell Biol 36: 2120-2124, 2004

61. Tworoger SS, Missmer SA, Eliassen AH, Barbieri RL, Dowsett M and Hankinson SE: Physical activity and inactivity in relation to sex hormone, prolactin, and insulin-like growth factor concentrations in premenopausal women - exercise and premenopausal hormones. Cancer Causes Control 18: 743-752, 2007.

62. Richardson DR: The role of hypoxia and nitrogen monoxide in the regulation of cellular iron metabolism. J Lab Clin Med 141: 289-291, 2003. 